University of Nebraska - Lincoln

DigitalCommons@University of Nebraska - Lincoln

Entomology Papers from Other Sources

Entomology Collections, Miscellaneous

1988

\title{
Species Distribution and Characterization Studies of Sex-Limited Esterases Within the virgifera Group of Diabrotica (Coleoptera: Chrysomelidae)
}

\author{
Susan K. Ruud \\ Biosciences Research Laboratory, USDA-ARS, State University Station, Fargo, North Dakota 58105 \\ I. C. McDonald \\ Biosciences Research Laboratory, USDA-ARS, State University Station, Fargo, North Dakota 58105 \\ D. A. Gabrielson \\ Biosciences Research Laboratory, USDA-ARS, State University Station, Fargo, North Dakota 58105 \\ O. A. Johnson \\ Biosciences Research Laboratory, USDA-ARS, State University Station, Fargo, North Dakota 58105
}

Follow this and additional works at: https://digitalcommons.unl.edu/entomologyother

Part of the Entomology Commons

Ruud, Susan K.; McDonald, I. C.; Gabrielson, D. A.; and Johnson, O. A., "Species Distribution and Characterization Studies of Sex-Limited Esterases Within the virgifera Group of Diabrotica (Coleoptera: Chrysomelidae)" (1988). Entomology Papers from Other Sources. 99.

https://digitalcommons.unl.edu/entomologyother/99

This Article is brought to you for free and open access by the Entomology Collections, Miscellaneous at DigitalCommons@University of Nebraska - Lincoln. It has been accepted for inclusion in Entomology Papers from Other Sources by an authorized administrator of DigitalCommons@University of Nebraska - Lincoln. 


\title{
Species Distribution and Characterization Studies of Sex-Limited Esterases Within the virgifera Group of Diabrotica (Coleoptera: Chrysomelidae)
}

\author{
SUSAN K. RUUD, ${ }^{1}$ I. C. MCDONALD,${ }^{2}$ D. A. GABRIELSON, ${ }^{1}$ \\ AND O. A. JOHNSON ${ }^{2}$
}

Biosciences Research Laboratory, USDA-ARS,

State University Station, Fargo, North Dakota 58105

\begin{abstract}
Ann. Entomol. Soc. Am. 81(6): 954-963 (1988)
ABSTRACT Isozyme studies revealed the existence of an autosomal, male-limited esterase locus (Est- $m$ ) in species of the virgifera group of Diabrotica found in the United States. The locus is characterized by the presence of active and null alleles, and particular taxa are monomorphic or polymorphic for the presumptive Est-m variants. Investigations of the properties of an Est- $m$ form present in the western corn rootworm, Diabrotica virgifera virgifera LeConte, produced data to indicate that the enzyme is a carboxylesterase and a glycoprotein with a relative molecular weight of $78,000 \pm 8,680 \mathrm{SD}$. Additional work has shown that $E s t-m$ activity is localized in the accessory glands of virgin, adult males $12-14 \mathrm{~d}$ old. Moreover, the enzyme is passed to females during mating. The molecular properties of $E s t-m$, its sex-limited expression in the accessory glands of males, and its subsequent occurrence in mated females suggest strongly that it functions in some way in reproduction.
\end{abstract}

KEY WORDS Insecta, genetics, isozyme, electrophoresis

WE HAVE BEEN USING electrophoretic and gel staining techniques to gather data on enzyme variation among members of the virgifera group of the genus Diabrotica found in the United States; i.e., D. barberi Smith and Lawrence, D. cristata (Harris), $D$. lemniscata LeConte, D. longicornis (Say), D. virgifera virgifera LeConte, and $D$. v. zeae Krysan and Smith. The studies have represented part of a broadly based biosystematics research effort designed to clarify the relationships of pest species and closely related taxa in support of population management programs.

Our early investigations of adult populations of $D$. longicornis revealed a variable region of esterase banding in which electromorphs were expressed only in zymograms of adult males. Appropriate tests of inheritance were then performed; they confirmed the existence of a polymorphic and sex-limited autosome locus (designated Est-m) characterized by the presence of both active and null alleles. Similar electromorphs were not detected during concurrent surveys of esterases in the sibling species $D$. barberi. Nevertheless, experimental hybridization tests conducted between $D$. barberi and $D$. longicornis produced data suggesting that a null allele of $E s t-m$ was fixed in

Mention of a trade name or proprietary product, or of specific equipment, does not constitute a guarantee or warranty by the USDA, and does not imply its approval to the exclusion of other products that may be suitable.

1 Department of Bacteriology, North Dakota State University Fargo, N. Dak. 58105.

${ }^{2}$ Biosciences Research Laboratory, USDA-ARS, Fargo, N. Dak 58105 . native $D$. barberi populations (McDonald et al. 1982). More extensive surveys of field-collected material subsequently demonstrated the occurrence of additional allelomorphs as well as geographic clines in allelomorph frequencies in $D$. longicornis. Moreover, presumptive Est- $m$ electromorphs were noted in other virgifera group taxa. Collectively, the data on allelic distributions (i.e., geographic and interspecific patterns) provided a basis for hypothesizing that selection was important to the evolution and maintenance of the Est-m variation.

Consequently, studies of the Est-m locus were expanded to include work on the biological role(s) of these enzymes in or among individuals or populations. We have initially examined tissue distribution patterns and various molecular properties of a putative Est- $m$ found in D. v. virgifera. These investigations have indicated strongly that the Est-m enzymes function in some way in reproduction and represent the primary topic of discussion in this report. Additionally, we document data on all of the presumed Est- $m$ alleles detected during our electrophoretic surveys of the virgifera group complex. A complete account of alleles has not appeared previously, although McDonald et al. (1982) published some information related to laboratory populations of $D$. longicornis and D. barberi.

\section{Materials and Methods}

Insects. Field-collected and laboratory-reared adults were surveyed for the presence or absence 
of Est-m electromorphs in D. barberi, D. cristata, $D$. longicornis, D. v. virgifera, and D. v. zeae, whereas only field-collected material was used for work involving $D$. lemniscata. The field samples originated from various geographic locales within the range of each taxon. All collections were made on or near known host plants during periods of adult activity in the late summer or early fall. Beetles were usually sent live to the Northern Grain Insects Research Laboratory, USDA, at Brookings, S. Dak., where they were identified and sexed. The samples were then shipped on dry ice to Fargo, where they were stored at $-80^{\circ} \mathrm{C}$ until electrophoretic analyses were performed. All laboratoryreared specimens were obtained through J. L. Krysan at the Brookings facility.

Diabrotica $v$. virgifera was chosen as a model for Est-m characterization studies because the species was found to be monomorphic for a single Est- $m$ electromorph and is recognized as an important pest on corn (i.e., the western corn rootworm) throughout much of the United States cornbelt. Additionally, D. v. virgifera is routinely reared in large numbers for research purposes at the Brookings laboratory. Thus, it was possible to obtain samples of live beetles for our investigations throughout the year.

Sample Preparation for Electrophoresis. Whole bodies, body parts, or tissues of adult male or female beetles were generally ground in a sample buffer (SB) containing $0.03 M$ Tris-glycine and $20 \%$ sucrose, $\mathrm{pH} 8.3\left(4^{\circ} \mathrm{C}\right)$. The $\mathrm{SB}$ volumes and the insect samples varied according to the goals of the experiments performed on the Est- $m$ extracts. All homogenates were centrifuged one or two times at $1,300 \times g$ in a refrigerated centrifuge $\left(4^{\circ} \mathrm{C}\right)$. The resulting supernatants contained the Est-m enzymes and were stored temporarily at $-80^{\circ} \mathrm{C}$ or were used immediately for particular procedures.

Electrophoresis and Gel Staining. Vertical polyacrylamide gel electrophoresis (PAGE) was used in conjunction with histochemical staining to assay various insect extracts or supernatant fractions for esterase activity or general protein patterns. Electrophoresis was performed in ORTEC glass analytical cells (Ortec, Inc., Oak Ridge, Tenn.) using a $0.03 M$ Tris-glycine buffer ( $\mathrm{pH} 8.3$ ) and a gel system described by McDonald et al. (1975). Test samples were electrophoresed at $35 \mathrm{~mA}$ constant current. An extract of the house fly, Musca domestica L., was included as a control on all gels, and a particular band was then used to measure the relative mobilities ( $R m$ values) of the Diabroti$c a$ esterase or other protein forms. The control extracts originated from previously characterized house fly strains derived from single fertilized females (I. McDonald, unpublished data). Bromophenol blue was incorporated in the upper buffer and served as a tracking dye. Runs were normally terminated after the dye traveled $60 \mathrm{~mm}$ into a separating gel with exceptions as noted in the text.

Gels were stained for esterase bands by the meth- od of Narang et al. (1976), except that the dye components were dissolved in a $0.15 \mathrm{M}$ Tris buffer (pH 7.42). The gels were incubated in the dye solution at $37^{\circ} \mathrm{C}$ until esterase bands were detected (15-30 $\mathrm{min})$. A number of protocol variations involving Coomassie Blue R-250 or G-250 (Bio-Rad Laboratories, Richmond, Cal.) were used to stain gels for general protein (Dauterman et al. 1962, Diezel et al. 1972, Reisner et al. 1975, Blakesley \& Boezi 1977, Steiner \& Joslyn 1979, Reisner 1984). Additionally, protein bands were resolved using variations of a Bio-Rad silver stain kit procedure on gels initially stained with Coomassie Blue G-250 by the method of Steiner \& Joslyn (1979). In some cases, gels assayed for esterase activity likewise were stained for general protein using the Steiner and Joslyn technique.

Spectrophotometric Assay of Esterase Activity. Total esterase activity in tissue extracts containing Est $-m$ was measured spectrophotometrically after the enzymatic hydrolysis of the colorless substrate $p$-nitrophenyl acetate (PNPA) to yield the colored product $p$-nitrophenol (PNP; Lunday \& Farmer 1983). The extracts were prepared by homogenizing 25 pairs of male accessory glands in $0.4 \mathrm{ml}$ of $\mathrm{SB}$. The homogenate was centrifuged $(15 \mathrm{~min}$ at $1,300 \times \mathrm{g}$ ), and $20 \mu \mathrm{l}$ of a 1:10 dilution of the supernatant in SB was added to $960 \mu \mathrm{l}$ of $0.15 \mathrm{M}$ Tris buffer ( $\mathrm{pH} 7.42$ ). Twenty microliters of $0.1 \mathrm{M}$ PNPA dissolved in absolute methanol was then mixed with the enzyme preparation, and the change in absorbance was recorded at $410 \mathrm{~nm}$ during a 5 -min period. Cuvettes containing $1.0 \mathrm{ml}$ of the $0.15 M$ Tris buffer were used as blanks for the assay. Also, nonenzymatic hydrolysis of the substrate was measured in cuvettes containing $20 \mu \mathrm{l}$ of the PNPAmethanol and $980 \mu \mathrm{l}$ of the Tris buffer. Esterase activity was calculated from the Lambert-Beer formula using a molar extinction coefficient of 1.17 $\times 10^{4} \mathrm{M}^{-1} \mathrm{CM}^{-1}$. One unit of esterase activity was subsequently defined as the amount of esterase solution hydrolyzing $0.1 \mu M$ of PNPA per minute under the test conditions.

In vivo Distribution Studies of Est-m Activity. Initial tests to determine the location of $E s t-m$ activity within the insect were conducted by dissecting the heads, thoraces, abdomens, antennae, and legs from five $D$. v. virgifera males 5-10 d old. Particular anatomical structures were combined in $\mathrm{SB}$, and supernatants were recovered after homogenization and centrifugation. Electrophoretic and histochemical staining procedures were then performed to assay the various supernatants for Est-m activity. Later, similar Est-m assays were conducted on supernatants derived from digestive tracts, fat bodies, hemolymph, testes, accessory glands, seminal vesicles and vasa deferentia, or ejaculatory ducts. All tests were replicated using beetles 2-3, 5-7, or 12-14 d old.

Observations of Est-m distribution in males prompted additional testing to determine whether or not the enzyme was passed to females during 
mating. These tests consisted of interrupting copulating pairs of beetles at 15-min intervals during mating or allowing matings to proceed to completion. Whole-body or reproductive tissue extracts of the various beetles subsequently were analyzed electrophoretically for the presence or absence of Est- $m$ activity.

Est-m Inhibition and Substrate Specificity Tests. Enzyme inhibition and substrate specificity tests were conducted to categorize the Est-m enzyme of D. v. virgifera according to previously employed criteria (Mounter \& Whittaker 1953, Burnstone 1962, Booth et al. 1973, Shnitka 1974, Varma \& Frankel 1980). The inhibition studies consisted of exposing Est-m containing gels to inhibitors included in the stain buffer for $15 \mathrm{~min}$ at $37^{\circ} \mathrm{C}$ before the addition of the enzyme substrate ( $\alpha$-naphtyl acetate) and the coupling dye (Fast Blue RR). The Est- $m$ extract used for electrophoresis was prepared by pooling the supernatants from 30 pairs of male accessory glands ground separately in 200 $\mu \mathrm{l}$ of SB; 20 -microliter aliquots from the pooled sample were then electrophoresed in the wells of replicate gels.

The inhibitors employed were diisopropyl fluorophosphate (DIFP; Sigma Chemical Company, St. Louis, Mo.), eserine (Sigma), $p$-hydroxymercuribenzoate (PHMB; Sigma), Landrin (3,4,5-trimethylphenyl methyl carbamate; Shell Chemical Company, New York, N.Y.), ethyl parathion (Phaltz and Bauer, Inc., Stamford, Conn.), and carbaryl (Phaltz and Bauer). The inhibitors were tested at concentrations of $10^{-3} M$ and $10^{-4} M$ for eserine, Landrin, and $\mathrm{PHMB}$, and $10^{-4}$ for the other compounds. An additional test performed with carbaryl involved a second addition of material to the dye solution midway through the gel incubation period. All stain reactions were quenched in $7 \%$ acetic acid $20 \mathrm{~min}$ after the addition of the substrate and coupling dye to the stain buffer. The gels were then photographed using Ektachrome Daylight 64 Film in conjunction with CC30M and CC20C gelatin filters and backlighting. Circular punches of the resulting negatives corresponding to positive and negative areas of Est- $m$ banding were placed in the wells of 96-well polystyrene microtiter plates. Absorbance values were subsequently recorded for each well using a Titertek Multiskan MC microplate reader (620 nm; Flow Laboratories, McLean, Va.). Enzyme inhibition was quantified by comparing control versus inhibitor absorbance values after the subtraction of appropriate background values.

Pooled extracts like those used for the enzyme inhibition tests were likewise used for electrophoretic evaluations of $E s t-m$ substrate specificity. These evaluations were performed by visually comparing Est-m staining in zymograms developed with $\alpha$-naphthyl acetate versus the following alternate substrates; $\beta$-naphthyl acetate, $\alpha$ - or $\beta$-naphthyl propionate, $\alpha$-naphthyl myristate, $\alpha$-naphthyl laurate, and indoxylacetate (all substrates from Sigma). All gels were incubated for $30 \mathrm{~min}$ at $37^{\circ} \mathrm{C}$ in the dye solutions before the reactions were quenched. The use of visual comparisons of enzyme staining precluded problems associated with quantifying Est $-m$ bands that differed in color according to which substrate was employed in the dye mixture.

Tests for Lipoprotein or Glycoprotein in Est-m Preparations. Extracts of Est-m were prepared from the abdomens of individual $D$. v. virgifera males, and $20 \mu \mathrm{l}$ of each were electrophoresed in separate gels. Gel samples were stained for esterase to locate the Est- $m$ electromorph, and corresponding unstained gel sections were then analyzed for lipoprotein or glycoprotein by the methods of Brown et al. (1977). The lipoprotein tests were conducted by staining the gels for $24 \mathrm{~h}$ in $100 \mathrm{ml}$ of an aqueous solution containing $0.55 \mathrm{~g}$ Sudan black, $7.5 \mathrm{ml}$ acetic acid, and $70 \mathrm{ml}$ ethanol. Destaining was then accomplished at room temperature using two to three changes of $7.5 \%$ acetic acid. Glycoproteins were revealed by first fixing the unstained gel portions in $7.5 \%$ acetic acid at room temperature, then incubating in $0.2 \%$ aqueous periodic acid for 45 $\min$ at $4^{\circ} \mathrm{C}$. The gels were stained for $45 \mathrm{~min}$ in Schiff reagent prepared according to Humason (1972), except that $10 \mathrm{~g}$ of pararosaniline was substituted for basic fuchsin in the stain solution. Destaining was conducted at room temperature using two or three changes of $10 \%$ acetic acid.

A modified lectin overlay assay (Glass et al. 1981, Clegg 1982) directed against Est-m immobilized on nitrocellulose (NC) was used as a further test for glycoprotein. Male D. v. virgifera accessory gland extracts containing 4.7 units of total esterase activity were initially subjected to electrophoresis for the assay. Est- $m$ was then electroeluted from gel slices onto nitrocellulose (NC) using an electroblot apparatus available from Bio-Rad Laboratories, Richmond, Calif. The transblots were conducted for $24 \mathrm{~h}$ at $30 \mathrm{~V}$ (500 volt-h) using a 0.05 $M$ Tris-glycine buffer system $\left(4^{\circ} \mathrm{C}\right)$. Circular punches of $\mathrm{NC}(6 \mathrm{~mm})$ containing Est- $m$ were next placed in the wells of 96 -well flat-bottom microtiter plates. Nonspecific protein binding sites in the wells were blocked $(1 \mathrm{~h}$ ) with $0.2 \mathrm{ml}$ of $10 \%$ bovine serum albumin in phosphate-buffered saline (Garvey et al. 1977), which was further diluted 1:10 with distilled water for use (all phosphate-buffered saline employed for the assays additionally contained 1 $\mathrm{mM} \mathrm{CaCl}_{2}$ and $1 \mathrm{mM} \mathrm{MgCl}_{2}$ ). The blocking solution was removed and the saturated NC samples were incubated for $1 \mathrm{~h}$ at room temperature with $0.2 \mathrm{ml}$ of a concanavalin A-horseradish peroxidase conjugate (Sigma).

The plates were subsequently subjected to five 5-min washes with phosphate-buffered saline to remove any unbound material. Finally, $0.2 \mathrm{ml}$ of peroxidase substrate containing a 1:1 mix of ABTS solution [2,2'-azino-di-(3-ethyl-benthiazoline sulfonate); Kirkegaard and Perry Laboratories, Gaithersburg, Md.] and hydrogen peroxide was added to each well. The development of green color in 
the wells was diagnostic for the presence of glycoprotein. Control wells containing NC without Est- $m$ were used to check for background staining caused by glycoprotein impurities often present in commercially available bovine serum albumin. Another control involved the addition of $50 \mu \mathrm{l}$ of $0.1 \mathrm{M}$ PNPA to a blocked well; the development of a yellow color in the well then indicated the presence of esterase capable of hydrolyzing the acetate to form PNP.

Relative Molecular Weight Determination. The molecular weight (mol wt) of Est-m from $D$. $v$. virgifera was estimated by gel filtration on a Sephacryl S- 400 column ( 2.6 by $105 \mathrm{~cm}$; Pharmacia, Inc., Piscataway, N.J.). The column was calibrated with the protein standards ribonuclease $\mathrm{A}$, mol wt 3.700; chymotrypsinogen A, mol wt 25,000; ovalbumin, mol wt 43,000 ; bovine serum albumin, mol wt 68,000; catalase, mol wt 232,000; and Ferritin, mol wt 440,000 (Pharmacia). All calibration proteins were equilibrated in elution buffer $(0.15 \mathrm{M}$ Tris, pH 7.42) and chromatographed alone or in pairs. Blue Dextran 2,000 was used to determine the void volume of the column. Elution profiles were monitored with a UV photometer $(280 \mathrm{~nm}$ ) and given elution volumes were estimated from the peak fractions. The elution volume parameter, $\mathrm{K}_{w}$, was then calculated for each standard and plotted against the corresponding log mol wt to generate a standard curve. The $\mathrm{K}_{\mathrm{av}}$ value of $E s t-m$ was subsequently derived by the same procedure, and the mol wt was determined from the standard curve.

Partial Purification and Concentration of Est-m. Results from the gel staining and lectin binding assays for glycoprotein directed against $E s t-m$ suggested that lectin affinity columns might be used for enzyme purification. Thus, a column procedure was devised to recover glycoproteins from $D$. $v$. virgifera male accessory glands using the affinity support Affi-Gel Con A (Bio-Rad). Crude tissue extracts were prepared for the separations by first homogenizing 25 pairs of accessory glands in $1 \mathrm{ml}$ of a $0.15 M$ Tris application buffer $(\mathrm{pH} \mathrm{7.42)}$ containing $0.1 \mathrm{M} \mathrm{CaCl}_{2}$ and $0.1 \mathrm{M} \mathrm{MnCl}_{2}$. The homogenates were next centrifuged twice for $15 \mathrm{~min}$ at $15,000 \times g\left(4^{\circ} \mathrm{C}\right)$; the resulting pellets were discarded each time. The final supernatant contained Est $-m$ and was diluted to $5 \mathrm{ml}$ with the Tris buffer for use. The Affi-Gel Con A column (1 by $16 \mathrm{~cm}$ ) was prewashed with about $100 \mathrm{ml}$ of application buffer. One 5-ml sample of the Est- $m$ extract was subsequently applied to the support material, and washing was continued until the OD of eluted fractions $(255 \mathrm{~nm})$ was the same as that of the application buffer. A second Est- $m$ extract was loaded on the column and the washing and monitoring process was repeated. Specifically bound materials were then eluted (3-ml fractions) with application buffer containing $0.2 \mathrm{M} \alpha$-D-methylmannopyranoside. PAGE was performed on $20-\mu$ l portions of each final wash fraction to assay for the presence of $E s t-m$ and other proteins. Selected fractions con- taining Est- $m$ were then combined and simultaneously dialyzed (against application buffer) and concentrated to $\cong 1 \mathrm{ml}$ using a collodion dialysis membrane (avg retention $25,000 \mathrm{~mol} \mathrm{wt}$ ) in conjunction with a vacuum apparatus (Schleicher and Schuell, Inc., Keene, N.H.). PAGE was again performed to test $20-\mu \mathrm{l}$ samples of each concentrate for the presence or absence of Est-m and other proteins.

An enzyme immunosorbent assay (EIA) was used to estimate the recovery of Est- $m$ activity in samples concentrated from selected column fractions. The assay was initiated by incubating separate 25$\mu \mathrm{l}$ portions of concentrated and crude accessory gland extracts $\left(24 \mathrm{~h}\right.$ at $\left.4^{\circ} \mathrm{C}\right)$ in the wells of 96 -well round bottom polystyrene plates to adsorb Est-m to the well surfaces. The crude extract served as a control and contained approximately 1.5 units of total esterase activity. The plates were emptied, and nonspecific protein binding sites in each well were blocked for $40 \mathrm{~min}$ at $4^{\circ} \mathrm{C}$ with $0.3 \mathrm{ml}$ of $10 \%$ bovine serum albumin in phosphate-buffered saline diluted 1:15 with distilled water. The blocking solution was removed and $50-\mu \mathrm{l}$ samples of mouse ascites fluid containing an anti-Est- $m$ monoclonal antibody (IgM; I. McDonald et al., unpublished data) were added to the wells. The plates were then incubated with shaking for $10 \mathrm{~min}$ at room temperature followed by an additional $50-\mathrm{min}$ incubation at $4^{\circ} \mathrm{C}$. The supernatants were decanted, and each well was washed twice with $0.3 \mathrm{ml}$ of a wash solution $(0.02 \mathrm{M}$ imadazole-buffered saline with $0.2 \%$ Tween 20; Kirkegaard and Perry) diluted 1:20 with distilled water to remove unbound primary antibody.

Lyophilized goat-antimouse antibody $(0.5 \mathrm{mg}$, IgG and IgM; Kirkegaard and Perry) conjugated with horseradish peroxidase was rehydrated in $\mathbf{2 . 0}$ $\mathrm{ml}$ of distilled water. The reconstituted material was further diluted 1:100 with $10 \%$ bovine serum albumin in phosphate-buffered saline (diluted 1:10 with distilled water), and $0.2-\mathrm{ml}$ portions of the latter were incubated in each test well for $1 \mathrm{~h}$ at room temperature. The wells were again emptied and rinsed five times by filling each well with wash solution and quickly inverting the plates. Finally, $0.1 \mathrm{ml}$ of peroxidase substrate solution containing ABTS and hydrogen peroxide (1:1) was added to each well. The development of green color in the wells was diagnostic for the presence of Est-m. Absorbance values in all wells were recorded with a Titertek Multiskan MC microplate spectrophotometer $(414 \mathrm{~nm})$. The values obtained for wells containing the crude accessory gland extracts were then compared with those from wells containing concentrated fractions to derive estimates of Est-m recovery. Negative (10\% bovine serum albumin was incubated in the wells instead of Est-m) and positive controls were included on all plates to delineate background staining and to test the performance of the substrate and peroxidase labeled antibody, respectively. 
Table 1. Data on Est $-\boldsymbol{m}$ heterogeneity recorded among members of the virgifera group of Diabrotica

\begin{tabular}{lccc}
\hline \hline Taxon & $\begin{array}{c}\text { No. } \\
\text { presumed } \\
\text { alleles } \\
(\text { null })^{a}\end{array}$ & $\begin{array}{c}\text { Electromorph } \\
\text { relative mobilities } \\
\pm \mathrm{SD}^{b}\end{array}$ & $\begin{array}{c}\text { No. } \\
\text { populations } \\
\text { surveyed } \\
(\text { lab })\end{array}$ \\
\hline D. barberi & $0(1)$ & & $27(1)$ \\
D. cristata & $0(-)$ & $1.03 \pm 0.062$ & $4(1)$ \\
D. lemniscata & $3(1)$ & 0.90 & 3 \\
& & $0.70 \pm 0.026$ & \\
D. longicornis & $5(1)$ & $1.02 \pm 0.055$ & $24(1)$ \\
& & $0.91 \pm 0.023$ & \\
& & $0.80 \pm 0.018$ & \\
D. v. virgifera & $1(1)$ & $0.72 \pm 0.022$ & \\
D. v. zeae & $1(1)$ & $0.39 \pm 0.031$ & $12(2)$ \\
\hline
\end{tabular}

${ }^{a}$ Presence of a null allele was assumed when zymograms lacking Est- $m$ activity were observed in those taxa where Est- $m$ electromorphs existed; see text for information on $D$. barberi.

${ }^{b}$ Migration distance of house fly standard protein $=10.2 \pm 0.62$ $\mathrm{mm}$

\section{Results}

Est-m Variation Within the virgifera Group. Electrophoretic surveys of virgifera group populations revealed putative null alleles in conjunction with three versus five active alleles of $E s t-m$ in $D$. lemniscata and D. longicornis, respectively (Table 1). The locus was likewise polymorphic in $D . v$. virgifera and $D$. $v$. zeae, but the variation was characterized by the presence of an apparent null allele and a single active electromorph in both taxa. The common electromorphs of $D$. lemniscata (the $0.90 \mathrm{Rm}$ variant was observed only once in the populations examined) and seemingly comparable electromorphs of $D$. longicornis exhibited slightly different mobilities when mixed or when separate extracts of the two species were electrophoresed on the same gel. In contrast, the enzymatic forms of $D$. v. virgifera and $D . v$. zeae were indistinguishable by similar mixed-extract or side-by-side gel comparisons. D. barberi and D. cristata were classed as lacking $E s t-m$ enzymes, although zymograms of $D$. barberi males sometimes exhibited slight esterase activity in areas of gels where the faster migrating enzymes of $D$. longicornis or D. lemniscata occurred. McDonald et al. (1982) discussed evidence from interspecific hybridization tests between $D$. barberi and D. longicornis which suggested that a null allele of Est-m is fixed in $D$. barberi populations. However, there are presently no data to indicate that the Est-m locus occurs in D. cristata.

Est-m in vivo Distribution Studies. Initial PAGE analyses of selected anatomical structures showed that Est- $m$ activity was localized in the abdomens of virgin male $D$. $v$. virgifera (Table 2). Later investigations of abdominal tissues further demonstrated that the enzyme activity was restricted almost exclusively to the accessory glands, although zymograms of seminal vesicle and vasa deferentia extracts exhibited faint Est- $m$ banding activity
Table 2. Est-m activity in tissues of virgin $D$. v. virgifera males

\begin{tabular}{lc}
\hline \multicolumn{1}{c}{ Fraction $^{a}$} & Est $-m$ activity \\
\hline Antennae & -- \\
Heads & -- \\
Thoraces & -- \\
Legs & -- \\
Abdomens & +++ \\
Digestive tracts & -- \\
Fat bodies & -- \\
Hemolymph & -- \\
Accessory glands & +++ \\
Seminal vesicles plus vasa deferentia & + \\
Testes & -- \\
Ejaculatory ducts & -- \\
\hline
\end{tabular}

${ }^{a}$ Body parts or tissues from five males were combined for electrophoresis.

$b--$ to +++ equals no activity to strong activity, respectively.

(Table 2). There were no differences in the distribution of Est-m in beetles 2-3, 5-7, or 12-14 d old.

Electrophoretic analyses of whole-body extracts clearly demonstrated the presence of Est- $m$ in females that had been in copulation for $\cong 1.5 \mathrm{~h}$ or longer (Fig. 1). Enzyme activity was likewise apparent in females assayed immediately after completing the mating process. In contrast, Est $-m$ band intensities appeared to be reduced in females electrophoresed 24 to $36 \mathrm{~h}$ after mating.

Est-m Characterization Tests. The organophosphates DIFP and ethyl parathion essentially suppressed Est- $m$ gel-staining activity as evidenced by absorbance readings which were reduced more than 98\% compared with a control when test gels were exposed to $10^{-4} M$ concentrations of either inhibitor (Table 3). Conversely, PHMB appeared to have a "synergistic" effect on Est- $m$ activity because absorbances recorded for treated gels were 10.7 and $24.1 \%$ greater than those of the controls when this material was present at concentrations of $10^{-4}$ $M$ or $10^{-3} M$, respectively. The carbamates, eser-

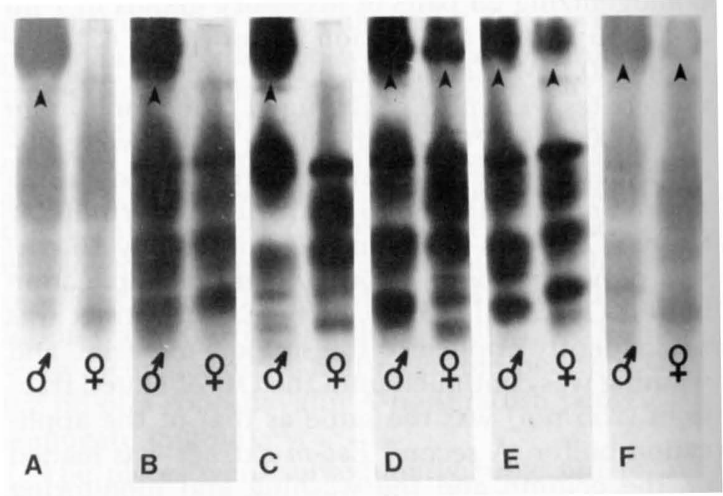

Fig. 1. Est- $m$ activity in whole-body extracts of $D$. v. virgifera adults. (A) Virgin beetles. (B-D) Beetle pairs interrupted during mating at 15-, 60-, and 105-min intervals, respectively. ( $\mathrm{E}$ and $\mathrm{F}$ ) Beetle pairs processed immediately or $24 \mathrm{~h}$ after mating, respectively. Arrows indicate Est- $m$ activity. 
Table 3. Comparison of Est-m staining intensities in polyacrylamide gels exposed to selected enzyme inhibitors

\begin{tabular}{lcc}
\hline $\begin{array}{c}\text { Material and } \\
\text { concentration }\end{array}$ & $\begin{array}{c}\text { Absorbance } \\
(620 \mathrm{~nm}) \text { minus } \\
\text { background }^{a}\end{array}$ & $\begin{array}{c}\text { \% Change in } \\
\text { absorbance }\end{array}$ \\
\hline arbaryl & & \\
Control & 0.704 & -26.1 \\
$10^{-4} M$ & 0.520 & -49.3 \\
$10^{-4} M+10^{-4} M^{b}$ & 0.357 & \\
DIFP & & -98.2 \\
Control & 0.605 & \\
$10^{-4} M$ & 0.011 & -24.2 \\
Eserine & & -66.6 \\
Control & 0.776 & \\
$10^{-4} M$ & 0.588 & -33.5 \\
$10^{-3} M$ & 0.259 & -43.0 \\
Landrin & & \\
Control & & \\
$10^{-4} M$ & 0.741 & -99.6 \\
$10^{-3} M$ & 0.493 & \\
Ethyl parathion & 0.422 & \\
Control & & \\
$10^{-4} M$ & 0.515 & \\
PHMB & 0.002 & \\
Control & & \\
$10^{-4} M$ & 0.516 & \\
$10^{-3} M$ & & \\
\hline
\end{tabular}

${ }^{a}$ Gels were photographed and absorbencies were recorded from the resulting negatives $(620 \mathrm{~nm})$. Values shown were derived by weraging absorbencies from two to three gel runs and subtracting u corresponding gel background value.

${ }^{b}$ A second addition of material was made to the dye solution midway through the gel incubation period.

ine, and Landrin caused partial, although progressively greater, reductions in Est- $m$ stain activity depending on whether gels were incubated with $10^{-4} \mathrm{M}$ or $10^{-3} \mathrm{M}$ concentrations of these materials; carbaryl exhibited a similar pattern of inhibition when one versus two additions of this carbamate were made to the dye solutions.

Est- $m$ staining reactions (Fig. 2) obtained with the substrate $\alpha$-naphthyl propionate (brown bands) were comparable with or slightly more intense than those obtained with $\alpha$-naphthyl acetate (brown

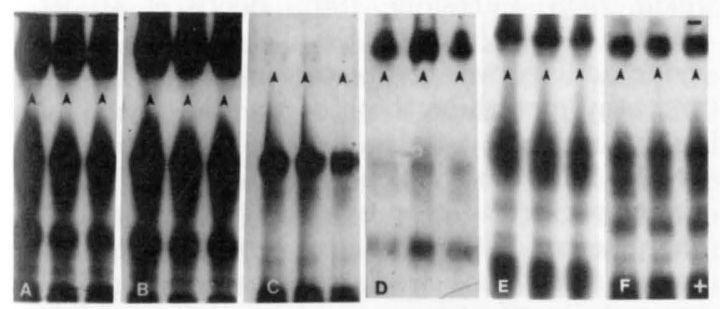

Fig. 2. Est- $m$ staining in acrylamide gels incubated with varying substrates. (A) $\alpha$-naphthyl acetate control. B) $\alpha$-naphthyl propionate. (C) $\alpha$-naphthyl butyrate. (D) Indoxylacetate. (E) $\beta$-naphthyl propionate. (F) $\beta$-naphthyl acetate. Arrows indicate Est- $m$ activity in individual electrophoretic lanes; only positive staining reactions are shown.

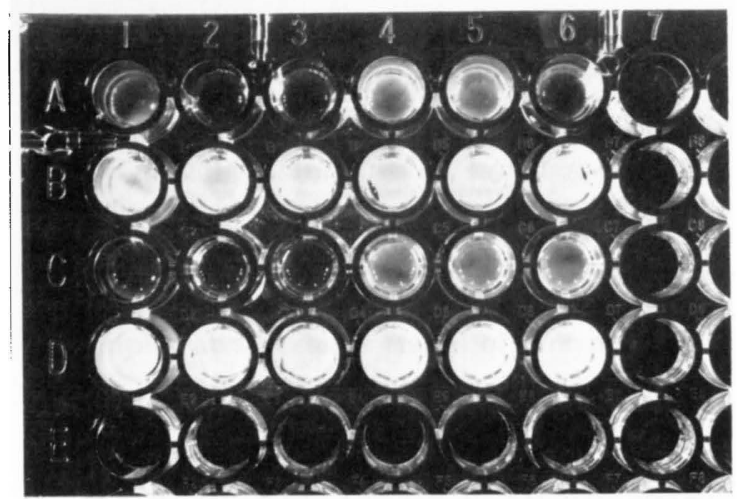

Fig. 3. Lectin-binding assay for the presence of carbohydrate in $E s t-m$ immobilized on nitrocellulose. Rows $\mathrm{A}$ and $\mathrm{C}$ show color development in replicate test wells $1-3$ or $4-6$ incubated with 0.1 or $0.01 \%$ solutions of a concanavlin A, horseradish peroxidase conjugate, respectively. Rows B and D show corresponding control wells lacking $E s t-m$.

bands). Est- $m$ bands were further resolved in tests using $\alpha$-naphthyl butyrate (brown bands), $\beta$-naphthyl acetate (pink bands), $\beta$-naphthyl propionate (pink bands), or indoxylacetate (blue bands), but band intensities were reduced to varying degrees relative to the $\alpha$-naphthyl acetate control. No bands were observed in tests with $\alpha$-naphthyl laurate or $\alpha$-naphthyl myristate.

Sudan black did not stain Est-m in acrylamide gels, thereby indicating that the enzyme was not a lipoprotein. However, a light pink band was resolved in the Est- $m$ area of gels subjected to the Schiff's staining procedure for glycoprotein. The lectin overlay assay directed against Est-m immobilized on NC provided further evidence to indicate that the enzyme is a glycoprotein because test wells developed a more intense green color in comparison with control wells following the addition of the concanavalin-A horseradish peroxidase conjugate and appropriate substrate (Fig. 3).

The standard curve constructed for molecular weight determinations by the sephacryl gel filtration technique is shown in Fig. 4. The relative molecular weight of Est-m from $D$. v. virgifera was estimated to be $78,680 \pm 8,680 \mathrm{SD}$. This estimate is a mean derived from six replicate experiments.

Partial Purification and Concentration of the Enzyme. Crude accessory gland extracts of $D . v$. virgifera males contained Est- $m$ along with a second esterase and twelve other proteins as assayed by PAGE and gel-staining techniques (Fig. 5). Electrophoretic analyses further showed that Est- $m$ was consistently eluted from the Affi-Gel Con A affinity column only when $\alpha$-D-methylmannopyranoside was included in the column wash buffer. Subsequently, Est- $m$ and two other protein bands (neither stained for esterase) were detected via electrophoretic assays of the dialyzed and concen- 


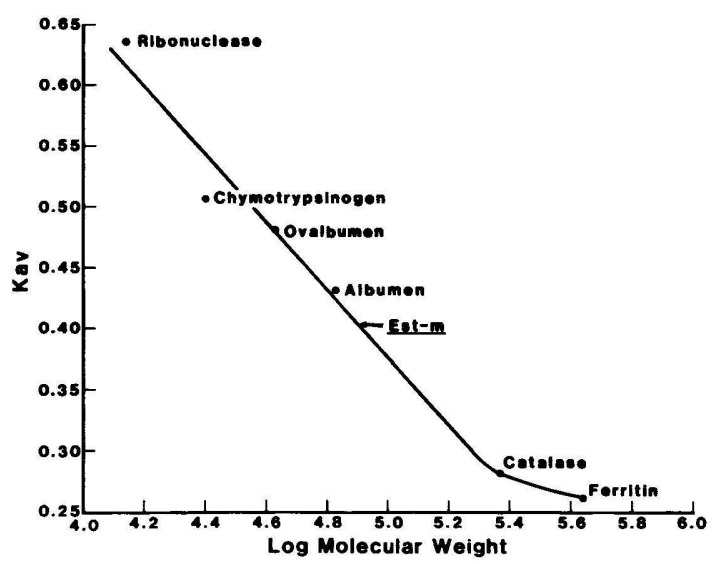

Fig. 4. Gel filtration standard curve used to estimate the relative molecular weight of Est-m from $D$. v. virgifera. $\mathbf{K}_{\mathrm{av}}=$ protein elution volume - column void volume (Blue Dextran 2000 elution volume)/total bed volume - column void volume. Text lists molecular weights of standards.

trated Est-m samples (Fig. 5). Twenty-five-microliter portions of crude accessory gland extracts (about 1.5 units of esterase activity) produced absorbance values approximating 0.400 in the EIA directed against Est-m. Absorbance values similarly obtained with the semipurified and concentrated samples approximated 0.575 , thereby indicating at least a $30 \%$ difference between the enzyme concentrations of the test versus control wells. By extrapolation the test wells contained the equivalent of about 2.2 units of esterase activity. This extrapolation is based on the assumption that Est-m was primarily responsible for the hydrolysis of PNPA in the enzyme activity assays conducted against the crude accessory gland extracts.

\section{Discussion}

The tissue distribution studies showed that Est-m enzyme activity was localized in the accessory glands of virgin $D$. $v$. virgifera males $12-14 \mathrm{~d}$ old. Thus, it seems likely that the enzyme is synthesized in the glands, although we cannot exclude the possibility that it is manufactured elsewhere and is transported to the glands before or just after adult eclosion. The enzymatic function of $E s t-m$ in the reproductive process is suggested by the sex-limited occurrence of the enzyme in the accessory glands and by its passage from males to females during mating. Unfortunately, we have no knowledge regarding the potential significance of null alleles at the Est-m locus. However, the involvement of accessory gland secretions in sperm transfer, sperm activation, inhibition of female remating, or other aspects of insect reproduction is well documented (Leopold 1976). Importantly, proteins and carbohydrates represent ubiquitous components of accessory gland secretions in Coleoptera (Anderson 1950, Gerber et al. 1971, deLoof \& Lagasse 1972,

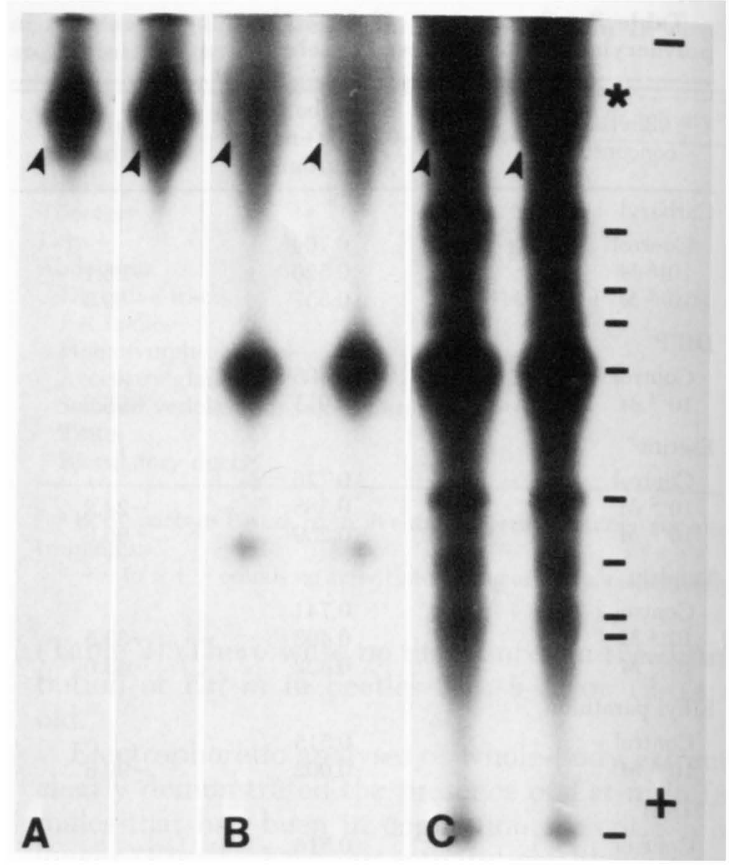

Fig. 5. Gel staining of affinity-purified concentrates or crude accessory gland extracts containing Est-m activity. (A) Affinity-purified concentrates stained for esterase. (B) Affinity-purified concentrates stained for esterase and general protein using Coomassie Blue G-250. (C) Crude accessory gland extracts stained for esterase and general protein using Coomassie Blue G-250. Arrows indicate areas of Est- $m$ activity, dashes indicate protein bands, and asterisk indicates area exhibiting three protein bands in the absence of esterase stain; the three bands are also present in Est-m null phenotypes.

Huignard \& Lamy 1972) or other insects (Davey 1958, Leopold 1970, Cantacuzene 1971), and most workers agree that these components are probably complexed as muco- or glycoproteins (Leopold 1976).

We are categorizing the Est-m enzyme of $D . v$. virgifera as a carboxylesterase based on the varying effects of inhibitors on its activity. Thus, the Est-m response pattern was similar to those observed previously with carboxylesterases (Mounter \& Whittekar 1953, Burnstone 1962, Booth et al. 1973, Shnitka 1974, Varma \& Frankel 1980) in that enzyme activity was completely inhibited by DIFP and ethyl parathion (both organophosphates), but not by carbaryl, Landrin, eserine (all carbamates), or PHMB at those concentrations tested. The substrate specificity tests provided evidence to further characterize Est-m as acting primarily on esters having side chains two to three carbons long. Also, some steric effects on enzyme activity were suggested because the gel-staining reactions of the $\alpha$-esters were more intense than their $\beta$-ester counterparts. The classification of $E s t-m$ is artificial and the in vivo substrates are unknown. However, enzymes similarly classed as carboxylesterases are widespread in insects and may be highly poly- 
morphic in natural populations. Moreover, these enzymes have been implicated as functioning in diverse processes such as digestion (Hipps \& Nelson 1974), chemical detoxification (Dauterman \& Hodgson 1978), reproduction (Richmond et al. 1980), or the regulation of juvenile hormone titers Whitmore et al. 1975).

The combined results of the Schiff's staining and concanavalin-A overlay assays indicated that Est-m of D. v. virgifera is most likely a glycoprotein. Both assays are diagnostic for the presence of glucose or mannose in carbohydrates, although positive Schiff's tests also are obtained against galactose and the methyl pentose, fucose (Sharon \& Lis 1972, Culling 1976). The specificity of concanavalin-A for Est-m was further demonstrated by the retention of the enzyme on the Affi-Gel Con A affinity column and its subsequent elution via column washings with buffer containing $\alpha$-D-methylmannopyranoside. Soluble glycoproteins are commonly present in cells or in the extracellular fluids of organisms. Evidence suggests that the carbohydrate substituents may function to stabilize protein configurations or they may serve as recognition markers in physiological processes such as cellular uptake (Sharon 1981). A protective role for the carbohydrate also has been suggested based on the observation that glycoproteins are more resistant to proteolysis in vitro than are nonglycosylated proteins (Sharon \& Lis 1981). Carbohydrate moieties appear capable of modifying various physical properties of proteins (e.g., electrical charge) without affecting their biological activities (e.g., see Cochrane \& Richmond 1979). Thus, it is possible that the intra- or interspecific mobility differences of $E s t-m$ electromorphs may reflect variations in the carbohydrate portions of the enzymes.

Our investigations have demonstrated that affinity chromatography using concavalin- $\mathrm{A}$ as a ligand represents a readily useable technique for recovering semipurified extracts of $E s t-m$. Moreover, the methodology, as described herein, has revealed two other presumptive glycoproteins of $D$. v. virgifera accessory gland extracts that may be worthy of further study. An obvious goal of future work will be to combine the column procedure with other techniques to obtain pure Est- $m$ preparations for more detailed analyses of the enzyme's biochemical and molecular properties. In this regard, we note here that the Bio-Rad Coomassie Blue G-250 assay was used to obtain early estimates of total protein in various Est- $m$ extracts. However, we have been unable to resolve Est- $m$ in acrylamide gels with either Coomassie Blue or silver stain, even though a number of staining protocols have been used and tests have been conducted against a variety of semipurified or crude $E s t-m$ preparations (e.g., containing material from up to 180 insects). We cannot completely exclude the possibility that the observed lack of staining is the result of low concentrations of Est- $m$ in the gels. Nevertheless, we currently favor the hypothesis that the carbo- hydrate portion of the enzyme, or possibly other structural peculiarities, somehow prevent Coomassie Blue or silver stain from reacting with enzyme moieties essential to stain uptake. The inability to stain Est- $m$ in gels has suggested that estimates of total protein recorded for given extracts by the Bio-Rad assay fail to reflect the $E s t-m$ content. Thus, we are currently investigating alternate approaches for estimating protein present in samples at successive stages of enzyme purification.

Est- $m$ represents the first documented instance of sex-limited esterase inheritance in Coleoptera. Furthermore, reports of sexual dimorphism in esterase expression are rare among insects in general, even though esterase studies have encompassed a wide variety of insect species. Steiner et al. (1983) genetically characterized a sex-linked esterase of the caddisfly, Triaenodes tardus Milne, in which enzyme activity was restricted to electrophoretic zymograms of females. In contrast, male-only esterase expression was reported in Anopheles stephensi Liston (Freyvogel et al. 1968) and A. funestus Giles (Green 1977). The last-named enzymes were described as sex-limited, although it was not determined whether they were sex-linked. Importantly, the enzyme activity was shown to be restricted to the accessory glands in A. funestus.

Male-limited esterases have further been reported to occur in the ejaculatory ducts of various Drosophila species (Johnson \& Bealle 1968, Sheehan et al. 1979). In this regard, a polymorphic EST-6 system of D. melanogaster Meigen has been studied extensively and shares characteristics analogous with those of Est-m. Thus, the EST-6 locus has been mapped to an autosome (chromosome 3 Wright 1963), and the variant enzymes have been classed as carboxylesterases as well as glycoproteins having molecular weights in the range of 60-65,000 (Sheehan et al. 1979, Mane et al. 1983a). The expression of EST-6 appears to be mediated by regulatory loci (Cochrane \& Richmond 1979, Tepper et al. 1982) and may be further modulated by juvenile hormone titers (Stein et al. 1984). The presence of the enzyme(s) in the male ejaculate has been associated with effects on sperm utilization, female fecundity, and the timing of female remating (Richmond et al. 1980; Gilbert 1981; Gilbert et al. 1981a,b; Gilbert \& Richmond 1982). It was suggested earlier that EST-6 hydrolyzed a maleproduced acetate ester to its alcohol in the female and that the alcohol then acted to reduce the attractiveness of mated females to courting males (Mane et al. 1983b). However, Vander Meer et al. (1986) have questioned whether such a mechanism of pheromone production operates in vivo based on direct chemical analyses of the postulated system components in the reproductive tracts or cuticle of mated insects. Oakeshott et al. (1987) recently cloned the EST-6 gene and characterized the enzyme as a serine hydrolase. Enzymes identified as serine hydrolases possess a serine residue 
at their active site and appear to be functionally related. Various carboxyl-, choline-, and aliesterases fall within the group along with the homologous family of serine proteases (Davis et al. 1985, Rogers 1985, Schumacher et al. 1986).

Finally, an S-esterase found among various members of the virilis group of Drosophila is coded for by a structural gene on autosome 2 and is likewise a carboxylesterase (Korochkin et al. 1976a,b, 1978a). The activity levels of S-esterase vary among strains and species within the group, and Korochkin et al. (1978a,b, 1981) reported evidence to indicate that enzyme expression may be modified by genes acting at both the levels of transcription and posttranscription. Also, Korochkin et al. (1976a,b) noted that S-esterase exhibits lipase activity and theorized that it somehow promotes fertilization via the breakdown of lipid materials in the female reproductive system.

\section{Acknowledgment}

The research reported was performed in partial fulfillment of the requirements for an M.S. degree in microbiology by Susan K. Ruud. This paper is published with the approval of the Director of the North Dakota Agricultural Experiment Station as journal article no. 1674 .

\section{References Cited}

Anderson, J. M. 1950. A cytological and cytochemical study of the male accessory reproductive glands in the Japanese beetle, Popillia japonica. Biol. Bull. 99: 49-64.

Blakesley, R. W. \& J. A. Boezi. 1977. A new staining technique for proteins in polyacrylamide gels using Coomassie Brilliant Blue G-250. Anal. Biochem. 82: $580-582$

Booth, G. M., J. Conner, R. A. Metcalf \& J. R. Larsen. 1973. A comparative study of the effects of selective inhibitors on esterase isozymes from the mosquito Anopheles punctipennis. Comp. Biochem. Physiol. 441B: 1185-1195.

Brown, S. E., R. L. Patton, R. J. Zerillo, S. M. Douglas, J. P. Breillatt \& M. H. Mazzone. 1977. Comparative properties of hemolymph of the gypsy moth and the European pine sawfly. J. N.Y. Entomol. Soc. 85: $36-42$.

Burnstone, M. S. 1962. Enzyme histochemistry and its application in the study of neoplasms. Academic, New York.

Cantacuzene, A. M. 1971. Recherches morphologiques et physiologiques sur les glandes annexes mâles orthoptères. I. Histophysiologie de l'appareil glandulaire de Schistocerca gregaria et Locusta migratoria. Bull. Soc. Zool. Fr. 92: 725-738.

Clegg, J. C. S. 1982. Glycoprotein detection in nitrocellulose transfers of electrophoretically separated protein mixtures using concanavalin- $\mathrm{A}$ and peroxidase: application to arenavirus and flavivirus proteins. Anal. Biochem. 127: 389-394.

Cochrane, B. J. \& R. C. Richmond. 1979. Studies of esterase 6 in Drosophila melanogaster. The genetics of a posttranslational modification. Biochem. Genet. 17: $167-183$.
Culling, C. F. A. 1976. Histology, pp. 876-1062. In S. S. Raphael [ed.], Lynch's medical laboratory technology. II. Saunders, Philadelphia.

Dauterman, W. C. \& E. Hodgson. 1978. Detoxification mechanisms in insects, pp. 541-577. In M. Rockstein [ed.], Biochemistry of insects. Academic, New York.

Dauterman, W. C., A. Talens \& K. Van Asperen. 1962. Partial purification and properties of flyhead cholinesterase. J. Insect Physiol. 8: 1-14.

Davey, K. G. 1958. The migration of spermatozoa in the female of Rhodnius prolixus Stal. J. Exp. Biol. 35: 694-701.

Davis, C. A., D. C. Riddell, M. J. Higgins, J. J. A. Holden \& B. N. White. 1985. A gene family in Drosophila melanogaster coding for trypsin-like enzymes. Nucl. Acid Res. 13: 6605-6619.

deLoof, A. \& R. Lagasse. 1972. The ultrastructure of the male accessory reproductive glands of the Colorado beetle. Z. Zellforsch. 130: 545-552.

Diezel, W., G. Kopperschlager \& E. Hofman. 1972. An improved procedure for protein staining in polyacrylamide gels with a new type of Coomassie Brilliant Blue. Anal. Biochem. 48: 617-620.

Freyvogel, T. A., R. L. Hunter \& E. M. Smith. 1968. Nonspecific esterases in mosquitoes. J. Histochem. Cytochem. 16: 765-790.

Garvey, J. S., N. E. Cremer \& D. H. Sussdorf. 1977. Methods in immunology. Benjamin-Cummings, Reading, Mass.

Gerber, G. H., N. S. Church \& J. G. Rempel. 1971. The anatomy, histology, and physiology of the reproductive system of Lytta nuttali. Can. J. Zool. 49: 523-533.

Gilbert, D. G. 1981. Ejaculate esterase-6 and initial sperm use by female Drosophila melanogaster. J. Insect Physiol. 27: 641-650.

Gilbert, D. G. \& R. C. Richmond. 1982. Esterase 6 in Drosophila melanogaster: reproductive function of active and null alleles at low temperature. Proc. Natl. Acad. Sci. USA 79: 2962-2966.

Gilbert, D. G., R. C. Richmond \& K. B. Sheehan. 1981a. Studies of esterase 6 in Drosophila melanogaster. VII. Remating times of females inseminated by males having active or null alleles. Behav. Genet. 11: 195-208.

1981b. Studies of esterase 6 in Drosophila melanogaster. V. Progeny production and sperm use in females inseminated by males having active or null alleles. Evolution 35: 21-37.

Glass, W. F., Jr., R. C. Briggs \& L. S. Hnilica. 1981. Use of lectins for detection of electrophoretically separated glycoprotein transferred onto nitrocellulose sheets. Anal. Biochem. 115: 219-224.

Green, C. A. 1977. A sex-limited esterase in the accessory glands of males of Anopheles funestus. Mosq. News 37: 46-48

Hipps, P. P. \& D. R. Nelson. 1974. Esterases from the midgut and gastric caecum of the American cockroach, Periplaneta americana (L.). Isolation and characterization. Biochim. Biophys. Acta 341: 421436.

Huignard, J. \& M. Lamy. 1972. Etude de l'evolution des protéines du spermatophore après l'accouplement, chez Acanthoscelides obtectus. C. R. Acad. Sci. (Paris) 275: 1067-1070.

Humason, G. L. 1972. Animal tissue techniques. Freeman, San Francisco. 
Johnson, F. M. \& S. Bealle. 1968. Isozyme variability in species of the genus Drosophila. V. Ejaculatory bulb esterases in Drosophila phylogeny. Biochem. Genet. 2: 1-18.

Korochkin, L. I., E. S. Belyaeva, N. M. Matveeva, B. A. Kuzin \& O. L. Serov. 1976a. Genetics of esterases in Drosophila. IV. Slow-migrating S-esterase in Drosophila of the virilis group. Biochem. Genet. 14: 161-182.

1976b. Nature of the organ-specific slow s-esterase in Drosophila of the virilis group. Genetika 12: 77-88.

Korochkin, L. I., N. M. Matveeva, B. A. Kuzin, G. I. Karasik \& L. F. Maximovsky. 1978a. Genetics of Drosophila. VI. Gene system regulating the phenotypic expression of the organ specific esterase in Drosophila virilis. Biochem. Genet. 16: 709-726.

1978b. Regulation of gene activity in eukaryotes. I. Interaction of genes controlling the synthesis of organ-specific esterase in Drosophila of the virilis group. Genetika 14: 632-643.

Korochkin, L. I., V. A. Godovikova \& B. A. Kuzin. 1981. Regulation of gene activity in eukaryotes. II Functional features of modifier genes controlling expression of organ-specific esterase isozyme in the Drosophila virilis group. Genetika 17: 128-136.

Leopold, R. A. 1970. Cytological and cytochemical studies on the ejaculatory duct and accessory secretions in Musca domestica. J. Insect Physiol. 16: 18591872.

1976. The role of male accessory glands in insect reproduction. Annu. Rev. Entomol. 21: 199-221

Lunday, A. J. \& J. L. Farmer. 1983. Tissue localization of esterase-5 in Drosophila pseudoobscura. Biochem. Genet. 21: 453-463.

Mane, S. D., C. S. Tepper \& R. C. Richmond. 1983a. Studies of esterase 6 in Drosophila melanogaster. XIII. Purification and characterization of the two major isozymes. Biochem. Genet. 21: 1019-1040.

Mane, S. D., L. Tompkins \& R. C. Richmond. 1983 b. Male esterase 6 catalyzes the synthesis of a sex pheromone in Drosophila melanogaster females. Science 222: 419-421.

McDonald, I. C., A. C. Terranova, O. A. Johnson \& R. A. Leopold. 1975. Polymorphisms and inheritance patterns of tetrazolium oxidase and octanol dehydrogenase in the house fly. J. Hered. 66: 218-220.

McDonald, I. C., J. L. Krysan \& O. A. Johnson. 1982. Genetics of Diabrotica (Coleoptera: Chrysomelidae): inheritance of xanthine dehydrogenase, hexokinase malate dehydrogenase, and esterase allozymes in two subspecies of D. longicornis. Ann. Entomol. Soc. Am. 75: 460-464.

Mounter, L. A. \& V. P. Whittaker. 1953. The hydrolysis of esters of phenol by cholinesterases and other esterases. Biochem. J. 54: 511-559.

Narang, S., A. C. Terranova, I. C. MeDonald \& R. A Leopold. 1976. Esterases in the house fly: polymorphisms and inheritance patterns. J. Hered. 67 30-38.

Oakeshott, J. G., C. Collet, R. W. Phillis, K. M. Nielson, R. J. Russell, G. K. Chambers, V. Ross \& R. C. Richmond. 1987. Molecular cloning and characterization of esterase-6, a serine hydrolase of Drosophila. Proc. Natl. Acad. Sci. USA 84: 3359-3363.

Reisner, A. H. 1984. Gel protein stains: a rapid procedure. Meth. Enzymol. 104: 439-441.
Reisner, A. H., P. Nemes \& C. Bucholtz. 1975. The use of Coomassie Brilliant Blue G-250 perchloric acid solution for staining in electrophoresis and isoelectric focusing on polyacrylamide gels. Anal. Biochem. 64 509-516.

Richmond, R. C., D. G. Gilbert, K. B. Sheehan, M. Gromko \& F. M. Butterworth. 1980. Esterase 6 and reproduction in Drosophila melanogaster. Science 207: 1483-1485.

Rogers, J. 1985. Exon shuffling and intron insertion in serine protease genes. Nature (Lond.) 315: 458459.

Schumacher, M., S. Camp, Y. Maulet, K. MacPhecQuigley, S. S. Taylor, T. Friedmann \& P. Taylor. 1986. Primary structure of Torpedo californica acetylcholinesterase deduced from its cDNA sequence. Nature (Lond.) 319: 407-409.

Sharon, N. 1981. Carbohydrates. Sci. Am. 243: 90116.

Sharon, N. \& H. Lis. 1972. Lectins: cell agglutinating and sugar specific proteins. Science 177: 949-959.

1981. Glycoproteins. Chem. Eng. News 59: 21-44.

Sheehan, K., R. C. Richmond \& B. J. Cochrane. 1979. Studies of esterase 6 in Drosophila melanogaster. III. The developmental pattern and tissue distribution. Insect Biochem. 9: 443-450.

Shnitka, T. K. 1974. Esterases-nonspecific esterases, pp. 1-53. In M. A. Hayat [ed.], Electron microscopy of enzymes; principles and methods. III. Van Nostrand Reinhold, New York.

Stein, S. P., C. S. Tepper, N. D. Able \& R. C. Richmond. 1984. Studies of esterase 6 in Drosophila melanogaster-XVI. Synthesis occurs in the male reproductive tract (anterior ejaculatory duct) and is modulated by juvenile hormone. Insect Biochem. 14: 527-532.

Steiner, W. W. \& D. Joslyn. 1979. Electrophoretic techniques for the genetic study of mosquitoes. Mosq. News 39: 35-54.

Steiner, W. W., A. R. Brigham \& J. D. Unzicker. 1983. Genetic studies of the caddisfly, Triaenodes tardus Milne (Trichoptera: Leptoceridae). I. Evidence for a sex-linked esterase. Biochem. Genet. 21: 1203-1207.

Tepper, C. S., R. C. Richmond, A. L. Terry \& A. Senior. 1982. Studies of esterase 6 in Drosophila melanogaster. XI. Modification of esterase 6 activity by unlinked genes. Genet. Res. 40: 109-125.

Vander Meer, R. K., M. S. Obin, S. Zawistowski, K. B. Sheehan \& R. C. Richmond. 1986. A reevaluation of the role of $C I S$-vaccenyl acetate, CIS-vaccenol, and esterase 6 in the regulation of mated female sexual attractiveness in Drosophila melanogaster. J. Insect Physiol. 32: 681-686.

Varma, A. K. \& J. S. Frankel. 1980. A comparison of tissue esterases in the genus Barbus by vertical gel electrophoresis. Comp. Biochem. Physiol. 65B: 267273

Whitmore, D., E. Whitmore, L. I. Gilbert \& P. I. Ittercheriah. 1975. Studies on the carboxylesterases that catabolize the juvenile hormone of insects, pp. 707-719. In C. L. Markert [ed.], Isozymes. III. Developmental biology. Academic, New York.

Wright, T. R. F. 1963. The genetics of an esterase in Drosophila melanogaster. Genetics 48: 787-801.

Received for publication 30 October 1987; accepted 25 July 1988. 